\title{
A figura de Maria na festa de Caná em Jo $2,1-11$
}

\section{The figure of Mary in the feast of Cana in John 2, 1-11}

Nelson Maria Brechó da Silva

\section{Resumo}

Este artigo se desenvolve a partir do texto grego de Jo 2,1-11, do Sitzim-Leben, contexto vital, que mostra o breve diálogo entre Maria e Jesus. Em seguida, a delimitação e a estrutura do texto. No campo da análise, procura-se analisar a semântica do sinal em João, bem como na literatura veterotestamentária. Para João, o semeion, sinal, tem como função apontar e significar algo, seja para chamar a atenção, seja a fim de transmitir um determinado conhecimento. No caso de Ex 4,30-31, o ot, sinal, sugere a manifestação de Deus para o povo crer, ajoelhar e se inclinar diante de YHWH. Assim, em João, o gesto realizador não é apenas demonstrativo e sim expressivo do mistério pessoal de Jesus e da salvação que será comunicada à humanidade. Nesse sentido, a figura de Maria na festa de Caná, é essencial, porque ela é atenta e possui profunda sensibilidade para dialogar com o seu Filho. Ela é, ao mesmo tempo, a figura de mãe e discípula fiel, no intuito de que Jesus seja o centro da cena. Percebe-se, com isso, que a figura de Maria, abre vários horizontes para refletir sobre a pastoral no mundo atual. $\mathrm{O}$ modelo de discipulado mariano pode fornecer um olhar sensível e ativo, para ser contemplativo na ação.

Palavras-chave: Sinal. Festa. Jesus. Maria. Figura.

\section{Abstract}

This article develops from the instrumental translation of John 2,1-11, of the Sitz-im-Leben, of the vital context, which shows the brief dialogue between 
Mary and Jesus. Next, the delimitation and the structure of the text. In the field of analysis, we try to analyze the semantics of the sign in John, as well as in the Old Testament literature. For John, the semeion, sign, has the function to point and signify something, either to attract attention or to transmit a certain knowledge. In the case of Ex 4,30-31, the ot, sign, suggests the manifestation of God for the people to believe, kneel and bow before YHWH. Thus in John the fulfilling gesture is not only demonstrative but expressive of the personal mystery of Jesus and the salvation that will be communicated to mankind. In this sense, the figure of Mary in the feast of Cana, is essential, because she is attentive and has deep sensitivity to dialogue with her Son. She is, at the same time, the figure of mother and faithful disciple, so that Jesus is the center of the scene. With this, we can see that the attitude of Mary opens many horizons to reflect on pastoral care in today's world. The model of Marian discipleship can provide a sensitive and active look, to be contemplative in action.

Keywords: Sign. Feast. Jesus. Mary. Figure.

\section{Introdução}

A figura de Maria apresenta uma função de grande importância na literatura joanina. Por um lado, ela é mãe atenta e protetora de seu Filho e desejosa de que ele possa realizar os sinais que lhe possibilitem reconhecêlo como a própria Palavra que se fez carne. Ela ensina o singelo sentido da educação materna: amar, cuidar e contemplar.

Por outro, Maria é a discípula fiel, porque acompanha o seu Filho. Ela o observa e não o abandona na sua caminhada de querer cumprir a Vontade do Pai. A força do Espírito Santo permite com que Maria possa ser firme no seu discipulado. Ela aprende e procura sentir e saborear a atividade pública de seu Filho, que ela tanto o ama incondicionalmente. $\mathrm{O}$ amor que se depara com a dor da morte e que se abre ao futuro, na esperança de re-encontrá-Lo em cada irmão e irmã da comunidade.

Nesse sentido, no desejo de examinar a figura de Maria como mãe e discípula no texto joanino de 2,1-11, o artigo compreende os seguintes pontos. Primeiro, o texto com a tradução a partir do grego. Segundo, a problematização da perícope para discutir a forma com que João fala de Maria e de Jesus. Terceiro, o pano de fundo histórico no intuito de situar o 
Siz-im-Leben, contexto vital, da região de Caná, em virtude do cenário das Bodas completar a "semana inaugural". Quarto, a análise para mergulhar em cada versículo e descobrir as suas riquezas. Quinto, a recepção e o efeito do texto que envolve a pragmática, a fim de perceber o que essa mensagem provoca na época de Jesus e nas comunidades do decorrer da história. Na conclusão, a hermenêutica, a saber, a atualização das Bodas no mundo atual, tão essencial na compreensão dos "sinais" como elementos fundamentais para preparar o coração na vivência da cruz como ato glorioso de compromisso fiel ao Pai. Assim, nota-se no decorrer do artigo, de que a figura de Maria atua como mãe e discípula, ora na sua sensibilidade e discreta atuação na festa das Bodas de Caná, ora no gesto de permanecer ao pé da cruz, a fim de meditar sobre a experiência da morte que leva ao sentido de amar incomensuravelmente.

\section{Texto}

Quando se analisa a passagem de Jo 2,1-11, texto originalmente composto em grego, constata-se que esta pesquisa se baseia na vigésima oitava edição crítica da Novum Testamentum Graece. ${ }^{1}$ Para favorecer a compreensão do texto grego, bem como a sua tradução para o português, ambos são reescritos de forma sequenciada:

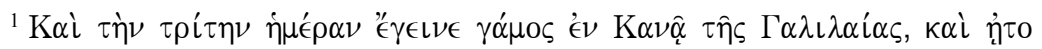

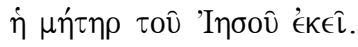

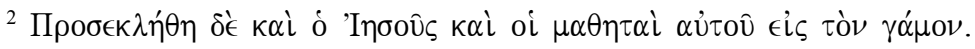

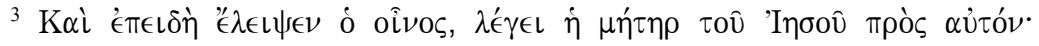

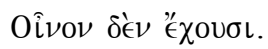

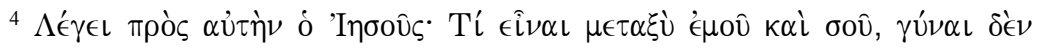

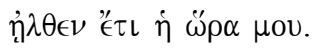

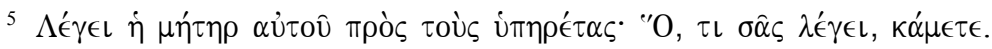

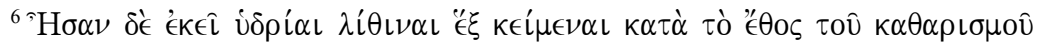

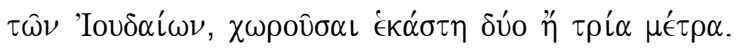

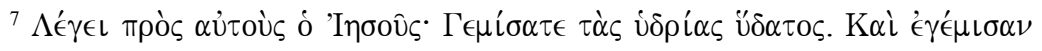

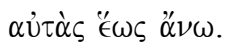

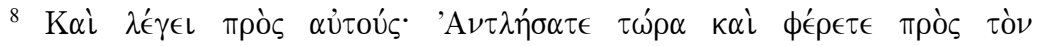

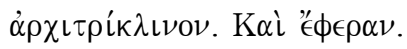

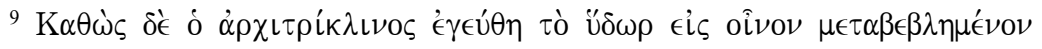

${ }^{1}$ NESTLE, E.; ALAND, K., Novum Testamentum Graece. 


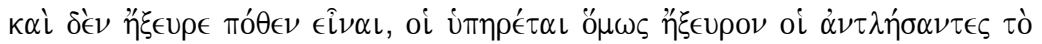

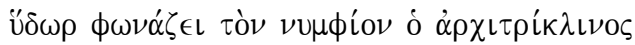

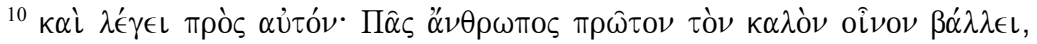

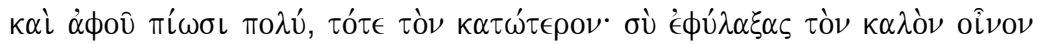
$\ddot{\epsilon} \omega \varsigma \tau \omega \dot{\rho} \alpha$.

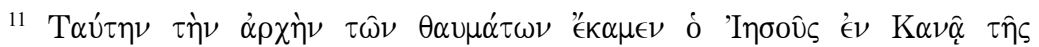

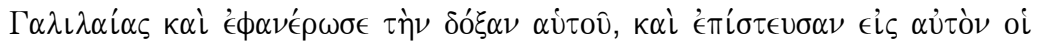

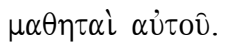

${ }^{1}$ E no terceiro dia houve casamento em Caná da Galiléia, e estava a mãe de Jesus lá.

${ }^{2}$ Também Jesus e os discípulos foram convidados para o casamento.

${ }^{3} \mathrm{E}$ faltando o vinho, disse a mãe de Jesus para ele: eles não têm vinho.

${ }^{4}$ Respondeu-lhe Jesus: o que é isso para mim e para ti, mulher; ainda não chegou a hora minha.

${ }^{5}$ Disse a mãe para os que estavam servindo, fazei tudo o que ele vos disser.

${ }^{6}$ Estavam ali seis talhas de pedra para a purificação dos judeus, cada uma contendo de duas a três medidas.

${ }^{7}$ Disse-lhe Jesus, enchei as talhas de água. E eles a encheram até a borda.

${ }^{8} \mathrm{E}$ disse-lhes: agora, tirai e levai ao encarregado da festa. E eles o levaram.

${ }^{9} \mathrm{O}$ encarregado da festa provou da água mudada em vinho, sem saber de onde viesse, embora os serventes soubessem de onde foi tirada a água, o encarregado da festa chamou o noivo.

${ }^{10} \mathrm{E}$ disse-lhe: todas as pessoas servem primeiro o bom vinho e quando já beberam bastante serve-se o inferior. Tu guardaste o bom vinho até agora.

${ }^{11}$ Este início dos sinais Jesus realizou em Caná da Galiléia e manifestou a glória para eles e creram nele os discípulos dele.

\section{Problematização da perícope}

Existem vários problemas no texto, tais como o sinal do vinho e o tempo de salvação, que são os dois tempos propostos pelo texto. A compreensão do sinal $^{2}$ do vinho depende de como deve ser interpretado o seu sentido simbólico. Nesse sentido, entra em jogo o retorno ao paraíso, tal como se percebe na apocalíptica dos judeus: no tempo final terá a abundância de bens

\footnotetext{
${ }^{2}$ O primeiro "sinal" realizado por Jesus indica o surgimento da nova humanidade, ou seja, o grupo daqueles que aderem Jesus pela fé (Gn 1,26-31: nesse dia Deus criou a humanidade). Prefere-se o "sinal" do que "milagre", porque não se trata de ato mágico e sim de acompanhamento com o Mestre, especialmente no desejo de se preparar para o momento de Sua paixão (Jo 19,25-27).
} 
terrenos e, sobretudo, do vinho (Dt 32,14). A partir deste fundo messiânico, não há dúvidas de que o sinal do vinho é o começo dos tempos messiânicos, em outras palavras, com Jesus começa a plenitude destes tempos. ${ }^{3}$

Quanto ao tempo de salvação, compara-se o texto joanino com Mc 1,19 onde Jesus diz: "Podem os filhos do noivo jejuar enquanto o noivo está com eles? Enquanto estão com o noivo não haverão de jejuar". Aliás, o próprio Jesus testemunha o início do tempo de salvação. ${ }^{4}$ Isso significa que o acompanhamento de Jesus com seus discípulos corresponde a uma grande festa. Os discípulos são convidados a ver, sentir e saborear a presença física do Mestre e de seu ensinamento com autoridade.

A palavra do Mestre implica escutar para que possa ver profundamente as coisas, porque a forma de ver permite contemplar e, consequentemente, a contemplação pode expressar muitas coisas. Maria enquanto discípula compreenderá isto junto à cruz de seu Filho (Jo 19,25-27). A visão da cruz provoca a contemplação, pois Maria, Maria de Clopas, Maria de Magdala e o discípulo permanecem lá. A dor do coração de Maria não a impede de permanecer unida ao seu Filho. O olhar de Jesus é muito envolvente, posto que se transforma em dizeres. Ele vê a sua mãe e pede para que ela veja o discípulo como filho e do mesmo modo o discípulo ver a mãe de Jesus como sua mãe. Assim, Maria e o discípulo escutam e acolhem a palavra de Jesus.

Na perícope de Jo 2,1-11, apresentam-se dois tempos. O primeiro é o de Jesus de Nazaré e, simultaneamente, o do passado de Israel, pois Jesus vem realizar uma promessa recebida por Israel através de uma experiência sem igual da relação com o Deus da Aliança. ${ }^{5} \mathrm{O}$ segundo tempo é o dos fiéis, que compreende o evangelista e seus leitores. Ambos situados depois da Páscoa e aos quais o Espírito dá plena inteligência das palavras e dos atos de Jesus. ${ }^{6}$

A primeira parte do Evangelho de João descreve especificamente a atividade pública de Jesus na Galiléia e na Judéia, até a véspera de sua morte. $\mathrm{O}$ arranjo das matérias parece regido por duas linhas estruturais, combinadas de maneira um tanto imprevisível. Primeiro, a linha temporal, a saber, depois de uma semana inaugural, continua numa sequência de festas judaicas e

\footnotetext{
${ }^{3}$ BLANK, J., O evangelho segundo João, p. 202-203.

${ }^{4}$ BLANK, J., O evangelho segundo João, p. 202-203.

${ }^{5}$ Nesta narrativa, Jesus pode ser comparado com Deus, ao passo que a sua mãe (mulher no sentido do texto) é a humanidade. Na figura da mãe, podem se acrescentar os criados. LÉÓNDUFOUR, X., Leitura do evangelho segundo João I, p. 174.

${ }^{6}$ LÉÓN-DUFOUR, X., Leitura do evangelho segundo João I, p. 172.
} 
culmina na semana final, os últimos dias de Jesus em Jerusalém. Segundo, a linha temática, em outras palavras, as sucessivas sequências podem, em princípio, ser organizados em torno dos "sinais" proféticos que Jesus realiza. Disso resulta a "semana inaugural", com - o sinal da água transformada em vinho: primeiro sinal em Caná (Jo 1,19-2,11). ${ }^{7}$

\section{Pano de fundo histórico}

Ao analisar o Sitz-im-Leben, contexto vital, observa-se que a narrativa precedente culminava com o anúncio de uma próxima manifestação do Filho do Homem em que céu e terra se encontram. Agora, a cena acontece em Caná $^{8}$ da Galiléia, pequena localidade de onde provém Natanael. Este lugar citado pelo historiador Josefo, localiza-se atualmente em Khirbet Kaná, 14 quilômetros aproximadamente ao norte de Nazaré. ${ }^{9}$

O episódio joanino de 2,1-11 parece dar sequência ao contexto de 1,1951. Se "no terceiro dia" (Jo 2,1) faz soma com os quatro dias de 1,19-51, deduz-se que o episódio de Jo 2,1-11 seria, assim, uma primeira ilustração da afirmação no fim do episódio anterior: "coisas maiores verás" $(1,50)$, e a "semana inaugural" terminaria em 2,11. ${ }^{10}$ Vale comentar brevemente que as descobertas de Qumran a respeito do Quarto Evangelho podem ser divididas em quatro fases. Primeiro, as descobertas e as primeiras concepções (19471955). Segundo, a efervescência sobre os Manuscritos (1955-1970). Terceiro, o período de estagnação (1970-1991). Quarto, o renascimento e a primavera de Qumran (1991[...]). ${ }^{11}$

\footnotetext{
${ }^{7}$ KONINGS, J., O evangelho segundo João, p. 94.

${ }^{8}$ A palavra hebraica "Caná" significa "adquirir". Jesus vai adquirir para si um povo com o qual realizará a nova aliança. BORTOLINI, J., Como ler o evangelho de João, p. 32.

${ }^{9}$ LÉON-DUFOUR, X., Leitura do evangelho segundo João I, p. 160.

${ }^{10}$ KONINGS, J., O evangelho segundo João, p. 112.

${ }^{11}$ A partir das descobertas de Qumran, as pesquisas apontaram as seguintes direções. Primeiro, obras como a Regra da Comunidade e Regra da Guerra e outros escritos, onde aparece o tema luz / trevas serviram perfeitamente de base para situar o Quarto Evangelho dentro do judaísmo do I séc. d. C.. Segundo, antes de ver o movimento de Jesus no Quarto Evangelho como gnóstico, os estudiosos começaram a perceber a relação com a tradição mosaica e profética em conformidade com textos como Dt 18,15-22. Terceiro, a função social da religião ganhou novas luzes a partir dos movimentos sectários. Quarto, o Logos joanino ganhou concepção judaica, implicando conexões com Gn 1 e Prov 8, ao invés de relacionar com especulações gnósticas. Quinto, o aumento de testemunhos da rica diversidade das expectativas messiânicas e judaicas e cristãs. Veja maiores informações no comentário de Paul Anderson, que se encontra
} 
Pode-se afirmar que, para o tempo do surgimento do Quarto Evangelho, é importante, por um lado, a questão de sua relação com os evangelhos sinópticos. Se o Evangelho segundo João pressupõe os sinópticos, principalmente se pressupõe os três, mal se pode datá-lo antes de 90 d. C. Por outro, aconselhase datar o Evangelho segundo João, pelo menos em relação ao seu conteúdo básico, antes das cartas de Inácio de Antioquia, situadas nos últimos anos do imperador Trajano (98-117 d. C.). As partes do Evangelho que se pode designar como "releitura" poderiam ser datadas depois da virada do século, mas não se tem indícios confiáveis a este respeito. Certo é que reagem às tendências gnósticas desse tempo; daí, entre outras coisas, a acentuação da "carne" de Jesus como lugar da salvação (Jo 1,14; 6,51-56). Um estudo mais penetrante das cartas de João leva ao resultado de que estas (a julgar por 1Jo $1,1-4$ ) antes pressupõem o Evangelho segundo João do que o inverso. ${ }^{12}$

Nota-se que estas observações apontadas servem para uma compreensão geral das discussões atuais em torno da composição do Quarto Evangelho. No entanto, para maiores esclarecimentos acerca deste assunto, sugere-se um aprofundamento na obra Qmran, and the Dead Sea Scrolls citada anteriormente. Com efeito, a reflexão deste artigo segue, agora, com a análise, no intuito de analisar a figura de Maria e no seu papel junto a Jesus na Festa de Caná.

\section{Análise}

Quanto ao gênero literário da narração, tem-se aqui, como afirma R. Bultmann, "uma típica história de sinal". ${ }^{13}$ Agora, segundo Konings, pode-se chamar também "narrativa de sinal". A narrativa consiste na manifestação de Deus no decorrer da história por meio de Jesus Cristo. Jesus presencia uma festa de casamento. Quando se nota a ausência de vinho, sua mãe o motiva a intervir. Depois de breve colóquio com a mãe, Jesus manda encher de água os jarros da purificação e servir essa água que, ao ser servida, revela-se vinho. ${ }^{14}$

Vale mencionar que o diálogo com a mãe representa uma "quebra na narrativa": Jesus parece resistir à sugestão de sua mãe (v.4). Essa quebra, de estilo joanina, fornece a chave de compreensão para o relato como João o

em: COLOE, M. L.; THATCHER, T., Qumran, and the Dead Sea Scrolls.

${ }^{12}$ BEUTLER, J., Evangelho segundo João, p. 32-33.

${ }^{13}$ BULTMANN, R., The Gospel of John a commentary, p. 115: "No que diz respeito à forma, temos aqui uma típica história de milagre".

${ }^{14}$ KONINGS, J., O evangelho segundo João, p. 112. 
entende, porque ainda não é a hora de Jesus. Mesmo que seja uma manifestação da glória, o trunfo de Jesus é apenas um "sinal", ${ }^{15}$ ou melhor, o início de sua obra e não a plenitude daquilo que vem realizar (v.11). ${ }^{16}$

Para LÉON-DUFOUR, o texto é uma "narrativa de milagre", ${ }^{17}$ que abrange a situação (v.1-2); pedido de intervenção (v.3-5); intervenção (v.6-8); constatação do prodígio (v.9-10); final admirativo (v.11). Desse modo, podese constatar que o sinal ${ }^{18}$ não é o ato de dynamis (poder) como é de costume nos sinópticos, mas semeion (sinal). Este termo joanino tem dois aspectos: primeiro, demonstrativo, o semeion suscita a fé dos discípulos em Jesus; segundo, ele manifesta a glória daquele que o opera. A fé é o objeto principal de cada semeion (Jo 20,31).

Beutler ${ }^{19}$ enfatiza o significado da mãe de Jesus ao pé da cruz (Jo 2, 1-11 forma inclusão com Jo 19,25-27). Maria, cujo nome não é mencionado, é percebida em seu papel feminino e histórico-salvífico, que transcende a individualidade. O tema da glória de Jesus aponta de antemão para sua consumação como aquele que será glorificado na sua morte na cruz e na ressurreição.

A construção da secção se percebe, sobretudo, na sequência dos diálogos. Os v.1-3a constituem a introdução narrativa da história. Nos v.3b-4 temos o diálogo entre Jesus e sua mãe, seguido, no v.5, de uma palavra da mãe aos auxiliares. O v.6 prepara narrativamente o sinal. Este se inicia no v.7 com uma ordem de Jesus aos auxiliares, seguida da execução. Segue-se uma segunda ordem de Jesus, com sua execução no v.8, em que aparece também o responsável da festa. Este, no v.9, constata a abundância surpreendente de vinho excelente, manda chamar o esposo e observa que ele guardou o vinho bom até esse momento (v.10). Então, a história se encerra, não com uma palavra de Jesus, mas com um comentário teológico do evangelista, que expõe o sentido profundo do acontecido.

\footnotetext{
${ }^{15}$ GRAYSTON, K., The Gospel of John, p. 32: “os sinais tem uma longa história na tradição profética Judaica. Alguns profetas realizam ações simbólicas impressionantes, que prefiguram o futuro e fazem com que isso aconteça. Os sinais de Jesus prefiguram o que é prometido e também revelam o que já está presente nele".

${ }^{16}$ KONINGS, J., O evangelho segundo João, p. 112.

${ }^{17}$ LÉON-DUFOUR, X., Leitura do evangelho segundo João I, p. 163-165.

${ }^{18}$ BULTMANN, R., The Gospel of John a commentary, p. 119: "Para o evangelista, o significado da história não está contido simplesmente no evento milagroso; este (evento milagroso), ou melhor, a narrativa, é o símbolo de algo que ocorre em todo o ministério de Jesus, ou seja, a revelação da dóxa de Jesus".

${ }^{19}$ BEUTLER, J., Evangelho segundo João, p. 81.
} 
A festa de casamento sustenta e unifica os símbolos. O matrimônio é no AT símbolo freqüente do amor de YHWH pela comunidade, amiúde personificada na capital (Is 62,5; Os 2; Is 1,21-26; 5,1-7; 49; 54; 62,1-9; Ez $16 ; \mathrm{Br} 4-5)$. No NT, é símbolo da união do Messias com a Igreja (Ef 5,3233.25; Mt 22,1-14; 25,1-13; 2Cor 11,1-4; Ap 12; 19,7-9; 21,2). O vinho é dom do amor: "tua boca é um vinho generoso" (Ct 1,2.4; 2,4; 4,10; 7,10 e 8,2) e se anuncia como dom messiânico (Am 9,13-14; Os 14,7; Jr 31,12; Is 25,6 e 62,9). É além disso símbolo do Espírito (At 2,15-16).

Seguem-se, nesse sentido, uma análise de cada versículo. O primeiro bloco, 2,1-3a coloca:

\footnotetext{
${ }^{1}$ E no terceiro dia houve casamento em Caná da Galiléia, e estava a mãe de Jesus lá.

2 Também Jesus e os discípulos foram convidados para o casamento.

${ }^{3 a}$ E faltando o vinho, $[\ldots]$
}

Estes versículos expõem a situação da narrativa, a começar com as indicações de tempo e lugar. O "terceiro dia" pode ser contado a partir do primeiro dia da vocação dos discípulos em 1,35 ou, mais provavelmente, a partir do indício cronológico anterior, em 1,43. Caná da Galiléia é mencionado também em 4,46 e se mostra um dos lugares preferenciais da atividade de Jesus. Surpreende que a mãe de Jesus seja mencionada antes dele; o texto não explica isso, nem histórica, nem teologicamente. ${ }^{20}$

Na passagem de 2,3, o vinho, que vem a faltar e depois se torna abundante e de melhor qualidade, simboliza a alegria dos tempos messiânicos. Vale afirmar, inclusive, que acabar o vinho é sinal trágico: "Já não bebem vinho entre canções, e o licor tem sabor amargo para quem o bebe" (Is 16,9-10; 24,9 e Jl 1,10).

A segunda divisão: 2,1-3b-4 acentua:

${ }^{3 b}$ disse a mãe de Jesus para ele: eles não têm vinho.

${ }^{4}$ Respondeu-lhe Jesus: o que é isso para mim e para ti, mulher; ainda não chegou a hora minha.

Nota-se que a narrativa propriamente inicia-se por um diálogo entre Jesus e sua mãe. Esta toma primeiro a palavra, o que corresponde ao papel de protagonista na narrativa, como já observamos, e chama a atenção de Jesus

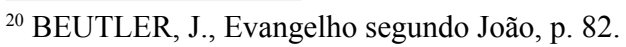


para fato de que o vinho começa a faltar. A resposta de Jesus, aparentemente dura quando tomada literalmente, tem paralelos veterotestamentários em Jz 11,$12 ; 2 \operatorname{Sm} 16,10 ; 19,22 ; 1$ Rs 17,18 . "Ainda não chegou a minha hora" deve ser entendido como afirmação e não como pergunta. De imediato, Jesus parece não atender o pedido de sua mãe para acudir ao jovem casal. Deste modo, o narrador liga a glória de Jesus em última instância à hora de seu enaltecimento na cruz em direção do Pai (Jo 12,23; 13,31-32). ${ }^{21}$

O capítulo 2,4 mostra que a resposta de Jesus à sua mãe quer chamar atenção para o fato de que a hora de sua manifestação como Messias de Israel ainda não chegou. Se, na sequência, ele realiza o que ela pede, isso significa que ele antecipa sua hora para atender a um pedido dela. No conjunto do Evangelho segundo João, isso é excepcional, uma vez que Jesus não se deixa levar diante das situações.

O terceiro bloco, que corresponde a 2,5 adverte:

${ }^{5}$ Disse a mãe para os que estavam servindo, fazei tudo o que ele vos disser.

Maria age como se não tivesse ouvido a resposta de Jesus. Ela dá ordem aos que estão servindo para que encham de água as talhas de pedra e, destarte, prepara o caminho para o "sinal". Na configuração atual do texto, sua atitude pode significar também que a revelação de Jesus pode começar a qualquer momento, talvez como antecipação da glória vindoura de Jesus em sua hora. ${ }^{22}$

Haja vista que em 2,5, as palavras da mãe de Jesus são as mesmas palavras do Faraó a propósito de José (Gn 41,55). Jesus apresenta-se, agora, como o novo José, aquele que salva a vida de seus irmãos.

O quarto bloco, 2,6-8, aponta:

${ }^{6}$ Estavam ali seis talhas de pedra para a purificação dos judeus, cada uma contendo de duas a três medidas.

${ }^{7}$ Disse-lhe Jesus, enchei as talhas de água. E eles a encheram até a borda.

${ }^{8} \mathrm{E}$ disse-lhes: agora, tirai e levai ao encarregado da festa. E eles o levaram.

Os versículos que agora se seguem relatam o diálogo entre Jesus e os que servem à mesa. Jesus toma as providências para o sinal da mudança de água para vinho que vai acontecer. As talhas vazias devem imediatamente

\footnotetext{
${ }^{21}$ BEUTLER, J., Evangelho segundo João, p. 82-83.

${ }^{22}$ BEUTLER, J., Evangelho segundo João, p. 83.
} 
ser enchidas com água. A observação acerca dos costumes da purificação dos judeus sugere a sequência "antigo/noivo" na ordem da salvação, que é característica da narrativa inteira. Remete-se à abundância da água do vinho a ser servido. Jesus ordena aos auxiliares que levem ao chefe da mesa algo da água com que encheram as talhas. O texto dá impressão de que a água só se transforma em vinho no momento de ser tirada das talhas e levada para a mesa; o enchimento das talhas ainda não produziu o "sinal". ${ }^{23}$

No 2,6, as seis talhas chegam a mais ou menos seiscentos litros, o que corresponde a uma abundância de vinho. O número 6 (são seis talhas), número abaixo da perfeição, que é o sete, pode significar que os ritos de purificação para os quais essas talhas eram usadas já não são mais necessários. De fato, uma vez usadas para fazer vinho, as talhas tornam-se impróprias para aqueles ritos.

No quinto bloco, que abrange 2,9-10, fala:

${ }^{9} \mathrm{O}$ encarregado da festa provou da água mudada em vinho, sem saber de onde viesse, embora os serventes soubessem de onde foi tirada a água, o encarregado da festa chamou o noivo.

${ }^{10} \mathrm{E}$ disse-lhe: todas as pessoas servem primeiro o bom vinho e quando já beberam bastante serve-se o inferior. Tu guardaste o bom vinho até agora.

Neste trecho, percebe-se que do diálogo seguinte entre o chefe da mesa e o esposo, conclui-se que aconteceu um sinal. Nenhum dos dois parece saber de onde vem este vinho excelente, que foi guardado até o fim, contrariamente aos costumes do país. Quem tem a última palavra não é Jesus, mas o chefe da mesa. Isso provavelmente tem algo da "ironia joanina". Em outros "apotegmas" a última palavra está, via de regra, com o protagonista principal nos evangelhos, normalmente Jesus. Será que isso significa que o responsável pela refeição é Jesus? ${ }^{24}$

O capítulo 2,10 elucida que a mudança da água em vinho simboliza a passagem da velha à nova economia. $\mathrm{O}$ vinho novo é o vinho melhor, "melhor que o amor" dos noivos humanos (Ct 1,2.4).

No sexto bloco, 2,11, considera:

${ }^{11}$ Este início dos sinais Jesus realizou em Caná da Galiléia e manifestou a glória para eles e creram nele os discípulos dele.

\footnotetext{
${ }^{23}$ BEUTLER, J., Evangelho segundo João, p. 83.

${ }^{24}$ BEUTLER, J., Evangelho segundo João, p. 83.
} 
O fim da narrativa é formulado pelo evangelista. Como foi mencionado, nem o chefe da mesa, nem o esposo sabiam de onde surgira o vinho bom. Só os discípulos de Jesus parecem ter percebido o que Jesus fez. Neste primeiro "sinal" revelou-se diante dos olhos deles, a "glória" de Jesus como Cristo e Filho de Deus. Eles viram "coisa maior", como tinha sido anunciado a Natanael $(1,50)$ - e verão mais ainda: "quando o Filho do Homem subir para onde ele estava primeiro" (Jo 6,62). ${ }^{25}$

Na passagem de 2,11, João utiliza dois termos para caracterizar os atos de poder realizados por Jesus: sinal e obra. Aqui, aparece o termo sinal, que é usado para mostrar que aquilo que Jesus realiza o credencia como o Enviado do Pai, da mesma forma como foi Moisés (Ex 4,1-9.30-31). O primeiro sinal realizado por Jesus é também a manifestação de sua glória, que confirma o chamado dos discípulos, que creram nele. $\mathrm{O}$ evangelista não menciona que a notícia tenha chegado aos convidados da boda. A finalidade do sinal não era essa.

A partir dos dados analisados acima, frisam-se, agora, alguns dados para maior clareza do sentido joanino. A palavra grega semeion tem originalmente o simples significado de "sinal, marca e característica", sem qualquer conteúdo teológico. Por conseguinte, o sentido de "sinal" não está, em si, ligado a ele. A palavra semeion tem como função apontar e significar algo, seja no sentido de chamar a atenção, seja na transmissão de um determinado conhecimento. Além do mais, possui ligação com a palavra hebraica ot que também significa "sinal e acontecimento". A principal função do semeion é indicar algo. ${ }^{26}$ Tanto no Novo Testamento como no Antigo, o semeion e o ot apresentam apontamentos especiais, como por exemplo, a manifestação de Deus e entre outros. O texto de Ex 4,30-31 desenvolve bem a dimensão do ot. Por esse motivo, faz-se uma tradução dela a partir da quarta edição crítica da Biblia Hebraica Suttgartensia, ${ }^{27}$ posto que texto joanino desta análise possui laço estreito com este trecho veterotestamentário:

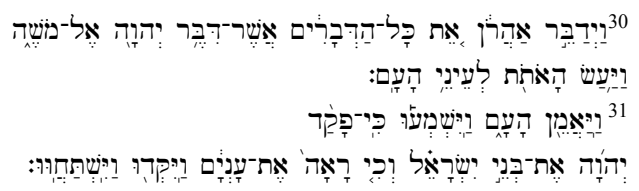

${ }^{25}$ BEUTLER, J., Evangelho segundo João, p. 83-84.

${ }^{26}$ BLANK, J., O evangelho segundo João, p. 195.

${ }^{27}$ ELLIGER, K; RUDOLPH, W., Biblia Hebraica Stuttgartensia. 
${ }^{30}$ E repetiu Aarão todas as palavras que tinha dito YHWH a Moisés.

E ele realizou os sinais à vista do povo.

${ }^{31} \mathrm{E}$ creu o povo. E ouviu porque visitara

YHWH os filhos de Israel e vira sua aflição, e eles se ajoelharam e se inclinaram.

Moisés, conforme se observa na tradução do hebraico para o português, age com o poder dos sinais para proporcionar a presença de YHWH no meio de seu povo. Este, por sua vez, crê, porque YHWH viu a sua aflição. Com efeito, as pessoas se ajoelham e se inclinam, pois temem YHWH. Nesse sentido, Jesus age como "novo Moisés" para preparar os seus discípulos. Aqui, nota-se a ligação veterotestamentária.

Ao relacionar o texto joanino com outros textos, nota-se que João se inscreve na tradição bíblica mais antiga, visto que por ocasião de maravilhas denominadas presentes em cada semeion, que Deus manifestou sua presença salvadora (Ex 3,20) ou autenticou seus enviados (Ex 4). Ora, em João, como, inclusive, nos profetas (Os 1-3; Is 20,2s; Jr 27,1-15) e nos sinópticos (a cura de um paralítico, o abrir os olhos a cegos e a reanimação dos mortos), o gesto realizador não é apenas demonstrativo e sim expressivo do mistério pessoal de Jesus e, enfim, da salvação que será comunicada aos homens. A novidade joanina acerca do sinal indica a preparação da comunidade para experimentar a glória no dia em que chegar, de fato, a hora de Jesus na cruz como momento de dor, de glória e de continuidade (Jo 19,25-27). A figura de Maria e do discípulo a quem Jesus amava sugere, dessa forma, a continuidade da missão, uma vez que o discípulo receberá Maria em sua casa.

$\mathrm{O}$ "terceiro dia" 28 abarca o indício de simbolismo, que indica um breve lapso de tempo ou se relaciona com a ação divina (Gn 22,4; 31,2; 34,25 e 40,20). Disso decorre que foi no "terceiro dia" que Deus entregou a Torah (Instrução) ao povo (Gn 19,11.15.16). É no "terceiro dia" que Deus socorre o povo (Lc 13,32) e que Jesus é por Deus ressuscitado (Jo 2,18).

Destaca-se no texto, em primeiro lugar, "a mãe de Jesus". Em seguida, ele mesmo com os seus discípulos. Na dimensão do simples relato, a menção prioritária da mãe pode corresponder a seu papel familiar ou social. Todavia, no

\footnotetext{
${ }^{28}$ SCHNACKENBURG, R., El Evangelio según San Juan, p. 367: "Mais peso tem a ideia de que o 'terceiro dia'aponta simbolicamente à manhã da ressurreição, especialmente se referirmos a 'hora' de Jesus à sua 'glorificação', e o 'sinal'de Caná é entendido como antecipação e promessa desta verdadeira manifestação de sua 'glória'”.
} 
nível do simbolismo joanino pode também ser uma forma de ilustrar a "mãe de Jesus" no início da obra, assim como será apresentada na "hora" da consumação.

Durante a festa, falta o vinho e Jesus fala para a "sua mãe": "que há entre mim e ti", forma de marcar distância ( $2 \mathrm{Sm} 19,23$ e Mc 1,24) ou, até mesmo, suspense (2Rs 3,13 e Os 14,8). O motivo do suspense aparece logo: "a minha hora ainda não chegou". Dessa forma, o que ele vai fazer agora é um semeion de sua competência, como explicita o próprio v.11, mas não a obra em si. Jesus age com soberania divina, nem sequer dirige ao mestre-sala para resolver o problema (v.10).

$\mathrm{Na}$ festa, há seis talhas de pedra (de duas a três medidas). Elas são de pedra (como o Talmud aconselha por causa da pureza) e serviam para as purificações rituais, que o judaísmo, especialmente de tendência farisaica, tanto estima. Só que elas estão lá deitadas, vazias e sem função. Com efeito, os utensílios do judaísmo ficaram inúteis, mas agora vão servir para uma realidade nova. Jesus dá às talhas um novo destino: manda enchê-las com água. É importante afirmar que, no simbolismo judaico, a água é associada à Torah (Instrução). No caso, essa não falta e o vinho sim. Logo, falta a alegria messiânica!

Os que servem à mesa, diáconos, realizam a ordem de Jesus. Quanto à expressão: "água feita vinho", não se diz como isso aconteceu, mas a voz passiva sugere uma actio Dei (ação de Deus) ou de seu enviado, sua Palavra criadora (Jo 1,3). Jesus manda levar essa água-vinho ao encarregado da festa, que não sabe "de onde" vem. O termo "de onde" em João, sempre leva a pensar acerca da origem última do dom ou do enviado de Deus (Jo 1,48; 2,9 e 3,8).

$\mathrm{O}$ encarregado da festa prova da água e percebe que é vinho. Jesus é quem providencia "agora" o vinho melhor e abundante do tempo messiânico (Is 25,6; Am 9,13-15). Ele faz a vez do Esposo do tempo final, anunciado pelos profetas que também anunciaram as novas núpcias (Aliança) de Deus com o povo (Is 62,5 e Ap 21,9 e 22,17). ${ }^{29}$

Em relação à pragmática, o sinal de Caná não aponta para um fornecimento espetacular de vinho e sim para a missão messiânica de Jesus, que ele realça mediante uma conotação interessante: Jesus mesmo está no centro da Aliança entre Deus e o povo, embora João evite essa palavra. ${ }^{30}$

Jesus inicia em Caná da Galiléia seus "sinais proféticos", de modo que ergue uma parte do véu da glória de Deus, que nele se esconde e se revela (Jo

\footnotetext{
${ }^{29}$ KONINGS, J., O evangelho Segundo João, p. 112-115.

${ }^{30}$ KONINGS, J., O evangelho Segundo João, p. 115.
} 
1,14.16 e 1,51). Com isso, os seus discípulos passam a crer nele. No entanto, ainda não é a atitude de fé madura e completa, que apenas será possível no término da obra de Jesus, quando não será mais preciso ver os "sinais". ${ }^{31}$

\section{Recepção e efeito do texto}

Ao realizar a pragmática para analisar a recepção e o efeito, nota-se que no contexto patrístico e medieval, Santo Irineu atribui a Maria a aspiração de participar antecipadamente na refeição eucarística. Já para Santo Agostinho, enquanto não tiver chegado para Jesus a hora da sua exaltação, Maria não pode intervir no ministério do seu filho, porque é somente na cruz que Jesus a reconhecerá em seu papel e que ela se tornará a mãe dos cristãos. ${ }^{32}$

Em relação à água, esta evidentemente foi recolhida na fonte ou no poço. É, portanto, conforme Santo Irineu, a água da criação original; a aliança de Deus, da qual o sinal de Caná é uma figura e é captada desde o seu primeiro estádio. De um modo geral, os Padres da Igreja registraram com freqüência o símbolo da água transformando-se em vinho: a aliança de Deus com Israel transfere-se para a nova aliança, tal como a água passa para o vinho. Para Santo Tomás, Jesus não veio abolir a lei e sim realizá-la. Isso assinala a continuidade do desígnio de Deus e, por isso, que o vinho vem a partir da água. ${ }^{33}$

No contexto moderno e contemporâneo, observa-se que a festa das bodas em Caná possibilita a cada membro atuante na comunidade a questionar a sua própria vida. Um questionamento que envolve tanto a maneira de pensar quanto a conduta. Desse modo, a festa é assimilada como o relacionamento entre Deus e Israel, ou melhor, Deus com o seu povo, a fim de cumprir a Palavra por intermédio da pessoa de Jesus.

\section{Conclusão}

Ao fazer a hermenêutica do texto joanino, constata-se, o quanto é indispensável nas celebrações e cultos que se realizam diariamente, fazer a experiência dos discípulos de ver na pessoa de Jesus, o Messias-Deus. É necessário viver realmente a Palavra de Deus, uma vez que ela é viva e atual. Jesus é a Palavra que se faz presente no meio de nós. Tal sinal nas bodas de

${ }^{31}$ KONINGS, J., O evangelho Segundo João, p. 115.

${ }^{32}$ LÉON-DUFOUR, X., Leitura do evangelho segundo João I, p. 162.

${ }^{33}$ LÉON-DUFOUR, X., Leitura do evangelho segundo João I, p. 184. 
Caná apresenta o poder de Deus e o papel da figura de Maria como mãe e discípula fiel. Um Deus que não é milagreiro, ${ }^{34}$ mas que convida a cada um a ver na pessoa de Jesus o rosto do Pai.

O vinho é a alegria, o ensinamento, a vida e o caminho que são expressos na pessoa de Jesus. Ele, na sua condição humana, revela-se na linguagem joanina ${ }^{35}$ como caminho, a verdade e a vida, pois, por meio dele, a Palavra não é aniquilada e sim realizada e plenificada. Disso urge uma mudança profunda na catequese, porque não se deve anunciar um Deus distante e sim de um Deus que se fez tão próximo e que viveu no meio de nós.

De acordo com Larrañaga, ${ }^{36}$ a mãe de Jesus desce com Ele em Cafarnaum (Jo 2,12). E o mesmo João coloca Maria entre diversas mulheres, junto à cruz de Jesus (Jo 19,25). Maria foi se comprometendo com o grupo de discípulos, transformando-se ela mesma em "discípula" de Jesus, não precisamente na condição de mãe humana, mas por uma atitude de fé. Aí está Maria, formando parte de um grupo de mulheres, ainda nos dias de Jesus, como em uma escola de formação. Não se sabe que grau de intimidade existiu entre Maria e essas mulheres. Seja como for, é óbvio que, sendo elas tão entusiastas seguidoras de Jesus, queriam saber de Maria os pormenores da infância; e perguntariam detalhes sobre certas épocas da vida de Jesus, sobre os quais ninguém sabia nada. A figura de Maria apresenta, com efeito, uma dimensão de discípula fiel, em razão de não abandonar Jesus e, pelo contrário, as dificuldades e provações possibilitam ainda mais a comunhão, o desejo de testemunhar e de viver, juntamente com as demais mulheres a dimensão do discipulado feminino.

$\mathrm{Na}$ visão de Clodovis Boff, ${ }^{37}$ Maria participa das festas do povo simples. Sua presença valoriza tais eventos, no caso, a realidade humana do casamento. Atenta ao curso da festa, Ela nota que vai faltar vinho. Misericordiosa, assume o problema dos outros. Mediadora, intervém junto ao Filho em favor dos noivos. Além disso, a mãe de Jesus orienta a atenção de todos em direção ao Messias, que é o verdadeiro "noivo", o grande protagonista de todo o episódio.

\footnotetext{
${ }^{34}$ Jesus não é milagreiro, porque a mensagem do milagre joanino é a irradiação deste corpo misterioso, ao mesmo tempo opaco e aberto ao crente. Enquanto que os profetas figuravam com seus corpos e em seus gestos todas as promessas da vida que o Senhor, por Moisés, tinha dado aos arcos.

${ }^{35}$ Yves Simoens sublinha o papel antropológico presente na literatura joanina como inata à sua maneira de redigir: "João, o teólogo, é um antropólogo nato". SIMOENS, Y., Évangile selon Jean, p. 10.

${ }^{36}$ LARRAÑAGA, I., O silêncio de Maria, p. 20.

${ }^{37}$ BOFF, C., Mariologia social, p. 81.
} 
Quanto a Ela, retira-se aos bastidores, como exemplo de todo evangelizador e educador popular. Assim, a preocupação de Maria é que não falte "vinho". Essa "necessidade imaterial" simboliza a alegria da festum Magnum (grande festa), o Sentido da vida, o dom da Graça e, enfim, o vinho escatológico da Glória.

A figura de Maria, mais especificamente na sua sensibilidade maternal, nota que Jesus pode iniciar os sinais. É imprescindível que Jo 2,1-11 aponta inicialmente a mãe e depois a pessoa de Jesus. Talvez isso significa a importância do ventre materno, que abarca o ensinamento do Antigo Testamento e que agora se une ao Novo no sentido de Jesus dar o início de sua condição de Filho de Deus. Maria, desse modo, indica o amor feminino, que é semelhante ao amor divino. Com efeito, há uma continuidade e descontinuidade na figura de Maria, porque o que ela sente (continuidade) se transforma em palavra (descontinuidade), pois ela fala com Jesus de que eles não têm mais vinho. Jesus, após meditar, realiza a transformação da água em vinho (descontinuidade) como princípio dos "sinais". Esta continuidade e descontinuidade também é presente em Jesus. Este é o mistério da fé cristã, porque a relação entre Maria e Jesus na festa vem trazer a alegria, de maneira que as ações de Jesus sejam incorporadas (continuidade) com o ensinamento do Pai pela força dinâmica do Espírito Santo. A descontinuidade de Jesus revela que ele é, de fato, a Palavra que se fez carne.

Enfim, o desafio é experimentar o vinho, que é Jesus, que tanto ama e que deseja se unir com cada pessoa. E mais: Deus caritas est (Deus é amor). Por essa razão, os "sinais" joaninos levam a experimentar e não a conceituar Deus, pois o conceito reduz Deus a um simples objeto de estudo. A figura de Maria na dimensão maternal e de discípula fiel permite abrir luzes para refletir sobre o papel do cristão no âmbito do discipulado. Ela ensina como mãe e aprende como discípula, porque ama Jesus e vive intensamente a vida, de modo a dar continuidade à missão de seu amado filho.

\section{Referências bibliográficas}

NESTLE, E.; ALAND, K. Novum Testamentum Graece. 28. Revidierte Auflage. Deutsche Bibelgesellschaft. Stuttgart: Deutsche Bibelgesellschaft, 2018. BEUTLER, J. Evangelho segundo João: comentário. São Paulo: Loyola, 2015. (Bíblica Loyola, 70).

BLANK, J. O evangelho segundo João. Petrópolis: Vozes, 1990. v. 4 / 1a. 
BOFF, C. Mariologia social: o significado da Virgem para a sociedade. São Paulo: Paulus, 2006.

BORTOLINI, J. Como ler o evangelho de João: o caminho da vida. São Paulo: Paulus, 1994.

BULTMANN, R. The Gospel of John a comentary. Oxford: Basil Blackwell, 1971.

COLOE, M. L.; THATCHER, T. Qumran, and the Dead Sea Scrolls: sixty years of discovery and debate. Atlanta: Society of Biblical Literatura, 2011.

ELLIGER, K; RUDOLPH, W. Biblia Hebraica Stuttgartensia. 4.ed. Stuttgart: Deutsche Bibelgesellschaft, 1997.

GRAYSTON, K. The Gospel of John. London: Epworth Press, 1990.

KONINGS, J. O evangelho segundo João: amor e fidelidade. São Paulo: Loyola, 2003. (Comentário Bíblico Latino-Americano).

LARRAÑAGA, I. O silêncio de Maria. São Paulo: Paulinas, 2012. (Coleção Em busca de Deus, 2).

LÉON-DUFOUR, X. Leitura do evangelho segundo João I. São Paulo: Loyola, 1996. v. 13.

SCHNACKENBURG, R. El Evangelio según San Juan. Version y comentario. Barcelona: Editorial Herder, 1980. t.I.

SIMOENS, Y. Évangile selon Jean. Éditions Facultés Jésuites: Paris, 2016.

Nelson Maria Brechó da Silva

Doutor em Filosofia pela Pontifícia Universidade Católica de São Paulo Docente do Departamento de Teologia da Faculdade João Paulo II Marília / SP - Brasil E-mail: nelsonbrecho@yahoo.com.br

Recebido em: 31/01/2019

Aprovado em: 16/01/2020 